\title{
ilbstracts.
}

mentologp.

\section{NEURO-ANATOMY AND NEUROPHYSIOLOGY.}

[1] The structure and connexions of the dentate nuclei of the cerebellum (Structure et connexions des noyaux dentelés du cervelet).- $\mathrm{V}$. Demole. Arch. Suisses de Neurol. et de Psychiat., 1927, xx, 271.

A LONG, elaborate, and finely illustrated study of the dentate nuclei in health and disease enables the author to draw the following conclusions, among others.

Structure.-The dentates are formed of two distinct parts, dorsomedian and lateroventral respectively. These differ in cells, fibres, and general dimensions.

Direct Connexions.-The dorsomedian part (microgyric, palæocerebellar) receives fibres from the dorsomedian section of the cerebellar cortex-the palæocerebellum; the lateroventral (macrogyric, neocerebellar), from the cortex of the lateral lobe-the neocerebellum.

Indirect Connexions.-Each dentate is in communication with the opposite cerebral hemisphere ; the dorsomedian region is in relation with the rolandic sensorimotor area (palæocerebral), the lateroventral with the sensory temporoparietal area (neocerebral). Because of the size of its cells andits connexions with the rolandic region the dorsomedian part of the dentate may be regarded as possessing some kind of motor function.

Crossed cerebellar atrophies.-When crossed cerebellar atrophy follows hemispheric lesions it predominates in the lateral lobe ; nuclear changes affect mainly the dentates and the nucleus emboliformis, whereas the $n$. globosus and roof ni clei are practically intact. Secondary atrophy of the dentate precedes that of the cerebellar cortex and can be detected two to three years after certain lesions of the internal capsule. The route of the atrophy is direct, via the pons and middle cerebellar peduncle, and retrograde, via the thalamus, nucleus ruber, and superior cerebellar peduncle. In longstanding cases the atrophy is not confined strictly to the appropriate cerebellar lobe ; it may cross the middle line and invade the other lobe, even reaching the inferior cerebellar peduncle and spinocerebellar fibre-systems. It is different from Wallerian degeneration in that it slowly involves linked series of neurones, and is progressive; further, it has a profound affect on structure and function, and throws light on some cases of chronic nervous diseases in which the symptoms become progressively worse.

S. A. K. W. 
[2] The role of the sympathetic nervous system in muscle tonus.- S. W. Ranson and J. C. Hinsey. Jour. of Comp. Neurol., 1926, xlii, 69.

A SERIEs of ten cats were sympathectomized, the left lumbar sympathetic cord being removed through a median abdominal incision. From 50 to 152 days intervened between sympathectomy and decerebration. Observations made before and after decerebration showed no constant variation between the hind limbs. Maintenance of extensor rigidity, presence of lengthening and shortening reactions, and resistance to passive flexion were equal in the normal and the sympathectomized hind limbs.

The conclusion is drawn that the sympathetic nervous system is not responsible for the exaggerated tonus of decerebrate rigidity.

In three of the sympathectomized cats tetanus toxin was injected in equal amounts subcutaneously over each femoral trochanter. Observations recorded from day to day did not show any constant variation in the posture of the two sides or in resistance to passive movement. The action of the toxin was apparently alike on the two sides.

The conclusion is reached that the exaggerated tonus caused by the injection of tetanus toxin is due neither to an action of the toxin on sympathetic endings in the muscle nor to its producing an increase in tonic discharges from the spinal cord by way of the sympathetic system.

In another series of twelve cats sympathectomized on one side observations were made at intervals of two days for two weeks following the operation. The authors were unable to observe any constant variation in posture on the sympathectomized side in standing, running, supporting the body weigkt on the hind limbs, or jumping from a table to the floor.

S. A. K. W.

[3] Electromyographic studies in different types of neuromuscular disturbances.-C. P. Richter and F. R. Ford. Arch. of Neurol. and Psychiat., 1928, xix, 660.

ELECTROMYOGRAMS from voluntary contractions in syringomyelia, progressive muscular atrophy and poliomyelitis are all similar, and all deviate widely from the normal. The authors suggest that these peculiar currents are characteristic for lesions of the anterior horn cells, common to these three different diseases.

The records from patients with muscular dystrophy also deviate from the normal, but in a different way. The primary waves are much more regular both in frequency and in amplitude than is usual in normal persons, and they are almost entirely free from all irregularities. The conclusion is reached that the primary waves in the myograms from the three patients with lesions of the anterior horn cells are produced by the proprioceptive impulses. On the other hand the records from patients with muscular dystrophy lend support 
to the view of Weizsäcker and Dusser de Barenne, who arrived at the conclusion that the primary waves are somehow produced by an inherent or autochthonous rhythmic activity of the motor horn cells.

R. M. S.

[4] The part played by the supravestibular connections in decerebrate rigidity.-L. J. J. Muskens. Jour. of Physiol., 1928, lxiv, 808.

In former publications on decerebrate rigidity writers have dealt with the subject primarily as physiologists, anatomical considerations coming second.

Forced movements backwards in the vertical plane, whether caused by a lesion of the primary vestibular centre, by section of ascending secondary connections, by lesion of the supranuclear centre near the posterior commissure or its palæostriatal connections, are probably always associated with a certain amount of rigidity, recalling Sherrington's "composite postural reflex, the antigravity muscles counteracting the superincumbent weight."

From different observations it is seen that there is a complete reversal of physiological effect at the level of the posterior commissure. (1) In a series of oral to caudal hemisections across the brainstem of a quadruped, temporary rigidity, homo- and hetero-lateral, is noted. (2) If an incision is made in the region of the posterior longitudinal bundle forced movements in the frontal and horizontal planes are directed reversely, according as the incision is on the caudal or the oral side of the commissure. (3) The same complete reversal is observed after faradic stimulation of the same region, when oral-caudal sections are made through the brain of primates.

Since section of the pyramidal tract has probably nothing to do with the origin of decerebrate rigidity, and as the nucleus ruber is frequently found intact, the part played by supravestibular connections in the production of the phenomenon may be supposed to be considerable. This applies especially to the ascending and descending tracts, lesion of which is associated with forced movements in the vertical plane.

S. A. K. W.

\section{NEUROPATHOLOGY.}

[5] Cerebral softening, its frequency, its site, and the state of the arteries in the affected region (Contribution à l'étude du ramollissement cérébral envisagé au point de vue de sa fréquence, de son siège et de l'état anatomique des artères du territoire nécrosé).--Forx and LEY. Jour. de Neur. et de Psych., 1927, xxvii, 658.

ThIs article was in preparation by the authors jointly at the time of Foix's death, and has been finished by the pupil, following as far as possible the former's ideas. Softening is considered to be synonymous with arterial blockage by thrombosis or embolism. 